\title{
Sentinel-lymph-node procedures in early stage cervical cancer: a systematic review and meta-analysis
}

\author{
Xiao-juan Wang $\cdot$ Fang Fang $\cdot$ Ye-fei Li
}

Received: 12 November 2014/Accepted: 18 November 2014/Published online: 28 November 2014

(C) The Author(s) 2014. This article is published with open access at Springerlink.com

\begin{abstract}
We performed a meta-analysis to assess the accuracy of sentinel-lymph-node (SLN) procedures for the assessment of nodal metastases in patients with early stage cervical cancer. Studies of SLN procedures for detecting nodal metastases in patients with early stage cervical cancer were systematically searched in MEDLINE and EMBASE between January 1, 2000 and August 30, 2013. We identified 49 eligible studies, which included 2,476 SLN procedures. The mean overall weighted-detection rate was 0.93 (95\% CI 0.92-0.94), at a pooled sensitivity of 0.88 (95\% CI $0.84-0.90)$ with limited heterogeneity $\left(\chi^{2}=80.57\right.$, degrees of freedom $\left.=47, p=0.002\right)$. Subgroup analysis of sensitivity and the rate of detection of different tracer techniques and surgery methods used in conjunction with an SLN procedures were as follows: studies using combined techniques, 0.88 (95\% CI $0.84-0.91$ ) and 0.97 (95\% CI 0.96-0.98); studies using metastable technetium-99, 0.87 (95\% CI 0.78-0.93) and 0.90 (95\% CI 0.87-0.93); studies using blue dye, 0.87 (95\% CI 0.79-0.93) and 0.87 (95\% CI 0.84-0.90); studies using laparotomy, 0.86 (95\% CI $0.80-0.90)$ and 0.87 (95\% CI 0.83-0.91); studies using laparoscopy, 0.90 (95\% CI 0.86-0.94) and 0.93 (95\% CI 0.90-0.96); and studies using robot-assisted surgery, $0.84(95 \%$ CI 0.72-0.92) and 0.92 (95\% CI 0.88-0.95). We concluded that the SLN procedure performs well diagnostically for
\end{abstract}

X. Wang · F. Fang $(\bowtie)$

Obstetrics and Gynecology Hospital of Fudan University, 419 Fangxie Road, Shanghai 200011, People's Republic of China e-mail: fangfang1968@hotmail.com

Y. Li

Cancer Hospital of Guangxi Medical University, 71 Hedi Road,

Nanning 500021, People's Republic of China the assessment of nodal metastases in patients with early stage cervical cancer.

Keywords Sentinel-lymph-node · Early cervical cancer · Meta-analysis $\cdot$ Nodal metastases

\section{Introduction}

Cervical cancer is the third most commonly diagnosed cancer and the fourth leading cause of cancer death in women worldwide with most cases occurring in developing countries [1]. Even with dramatic treatment changes, increased incidence and deaths due to cervical cancer continues to be a problem: 12,340 new cases and 4,030 deaths occurred in 2013, from 11,150 to 3,670 in 2007 in the USA [2, 3]. Cervical cancer diagnosis is made by cervical biopsy or conization. Although cervical screening is excellent for cancer prevention, this disease continues to be diagnosed in locally advanced stages. The Federation Internationale de Gynecologie et d'Obstetrique (FIGO) clinical staging system does not include evaluation of lymph node involvement, although lymph node metastasis is an important prognostic factor in cervical cancer in addition to parametrial cancer extension and positive surgical margins [4].

Radical hysterectomy with pelvic lymphadenectomy is the standard treatment for early stage cervical cancer. However, pelvic lymph node metastases are detected in $0-4.8$ and $0-17 \%$ of patients with stage IA and IB cervical cancer, respectively [5]. Moreover, lymph node involvement is observed in only $12-27$ and $25-29 \%$ of patients with stages IIA and IIB cervical cancer, respectively [6, 7], suggesting that about three quarters of all patients routinely received pelvic lymph node dissection despite the absence of metastasis. Lymph node dissection not only increases 
operative time and blood loss but also causes occasional leg lymphedema and nerve and blood vessel injuries [8]. Moreover, removal of "healthy" lymph nodes may negatively influence the immune system. Thus, in most patients with cervical cancer, lymph node dissection could be omitted.

Cabanas reported the existence of a so-called sentinellymph-node (SLN), confirming that this site was the first location of metastasis and that in clinically non-suspicious nodes, this node was frequently the only one affected [9]. When nodal metastases occur, the SLN will be initially involved and as such SLN biopsy has been implemented in the standard of care for patients with melanoma and breast cancer [9, 10]. If the SLN concept is valid in cervical cancer, most patients with early stage disease could avoid pelvic lymphadenectomy by both preoperative radioisotope injection of Tc99m or intraoperative blue dye with a confirmation of a metastasis-free SLN status. Because current studies offer inconclusive data about this procedure, we performed a meta-analysis to evaluate the diagnostic performance of SLN procedures with respect to sensitivity and early stage cervical cancer detection.

\section{Materials and methods}

\section{Search strategy and selection criteria}

A comprehensive systematic search for published studies was performed independently by Wang and Li from January 1, 2000 to August 31, 2013, using Embase and PubMed databases. Predefined search terms were used to identify reports about the diagnostic performance of the SLN procedure in patients with early cervical cancer. We used a search algorithm that was based on a combination of text words: "sentinel-lymph-node" AND "cervical cancer". Review articles, letters, comments, conference proceedings, unpublished data and case-reports were not selected for our study. We included studies meeting the following inclusion criteria: enrollment of at least 12 patients; prospective design to assess effectiveness of identification and diagnostic performance of the SLN procedure; most ( $>80 \%$ ) enrolled patients had early stage cervical cancer (FIGO I-IIA) and reported positivity rates (ie, a clearly described histopathological analysis and specimen-handling procedure). To avoid overlapping patient data in duplicate publications, we included the more recent articles with the largest sample size.

Reference standard and test results

The approach of this report differs from similar studies, because, in line with common clinical practice, the false-positivity rate was, by definition, zero. When the SLN is the only positive node identified, the SLN procedure is considered to be successful. The detection rate was calculated by the number of procedures in which at least one SLN was identified, divided by the total number of procedures undertaken. The sensitivity of the SLN procedure was defined as the number of true positives in patients with positive histopathological findings (true positives/[true positives + false negatives]). A true positive SLN was defined as a positive SLN identified with histopathological techniques (hematoxylin and eosin staining, serial sectioning, immunohistochemistry, or RT-PCR), independent of regional lymph node status. Sentinel-lymph-node procedure yielding tumor-negative sentinel node(s) in combination with tumor-positive non-sentinel nodes were classified as false negative.

\section{Data extraction}

Wang and $\mathrm{Li}$ extracted relevant data from all full-text publications using a standardized data abstraction form. They were blinded to the identity of study investigators and institution. The data extraction form was comprised of the following items: year of publication and origin, histopathological technique used, number of patients included, type of study design (prospective, retrospective, or unknown), and method of SLN identification (radiotracer or dye, method, and mode of injection).

To assess the quality and applicability of the studies included in this report, we used an established qualityrating system for diagnostic studies based on QUADAS [11]. Wang and $\mathrm{Li}$ independently reviewed each article to extract relevant study characteristics and results using a standard form. We divided the criteria list into two subgroups: internal and external validity. The criteria could be scored as "yes," "no," or "not mentioned" in the publication. The internal validity items focused on the validity of the reference test (histology), consecutive patients, blinded interpretation of pathological results, and prospective studies. The external validity items focus on stage of disease (FIGO), the type of patient population and spectrum, demographics, the inclusion/exclusion criteria, detection of sentinel node (SN) technique, localization of $\mathrm{SN}$ (and/or bilateral SN) described, scintigraphy, and description of SN criteria.

\section{Statistical analysis}

The sensitivity of the $\mathrm{SN}$ procedure was determined from the number of true positive (TP) and false-negative (FN) results from the $2 \times 2$ contingency table of the individual studies. Studies that did not present patients with tumorpositive sentinel node were excluded from statistical 
pooling of sensitivity but were included for pooling of the $\mathrm{SN}$ detection rate. The detection rate was defined as the percentage of procedures in which at least one sentinel node was identifiable. Because false-positive SLN procedures are impossible in our context, we set the specificity of the procedure at $100 \%$. Therefore, sensitivity was pooled with a random-effect analysis, without taking specificity into account. Potential heterogeneity of sensitivity results was analyzed with the Chi-squared test. We performed a subgroup analysis for the three SN detection techniques: Tc99m, blue dye, and the combination of both. Detection rates and sensitivity for studies using a laparotomic procedure versus studies using a laparoscopic procedure versus studies using a robot-assisted procedure were calculated. Pooled data are presented with $95 \%$ confidence intervals (95\% CI). All data were processed with the metan procedure in STATA version 11.0 (Stata Corp; Texas, USA) and Meta-DiSc version 1.4 (XI Cochrane Colloquium; Barcelona, Spain). In all analyses, a $p$ value of 0.05 or less indicated statistical significance.

\section{Results}

We identified 49 eligible studies (Table 1) [6, 7, 12-58]. Two studies [59, 60] were excluded because of insufficient cases, and eight studies were excluded because of duplicate publication [61-68]. Most patients were diagnosed as having early stage cervical cancer (FIGO I-IIA), but one study was excluded because more than $50 \%$ patients had stage IIb cancer [69]. Overall, 2,476 SLN procedures were included as eligible reports, and there were 39 eligible studies $[6,7,13,15,16,20-22,26,28-58]$ that met at least three of the four internal validity criteria (see Table 2). All studies used a valid reference test (histology) and had a prospective design. Both inclusion and exclusion criteria were offered in 27 studies [15, 26-37, 41-46, 49-54, 56, 57] (see Table 2), but the definition of a SLN varied among studies (variously defined as "blue," "hot," or "blue and hot").

Blue tracer dye varied from 0.2 to $4 \mathrm{ml}[13,41]$, and Tc99m activity (MBq) varied from 10 to $290 \mathrm{MBq}$ among studies [38, 59]. In 36 studies [13, 17, 18, 21, 22, 24-27, 30-37, 41-48, 50-52, 54-59], the four-quadrant method was used and four studies [14, 16, 20, 23] did not mention the number of peritumoral injections. In most studies [7, 14, 17-21, 24, 26-33, 36, 37, 40-46, 49-53, 55-58], immunohistochemical SNL staining was performed with hematoxylin and eosin (H\&E) and this was negative. SLN sectioning was not uniformly undertaken across studies, but serial sectioning was used in most papers [7, 14, 17, 19, $20,24-33,35,37,41,52,53,56]$ ranging from 0.2 to $5 \mathrm{~mm}$ sections [7, 20]. SLN identification was classified as in vivo or ex vivo.

Sensitivity for detecting lymph node metastases for all studies $(n=48)$ was 0.88 (95\% CI $0.84-0.90)$ (see Fig. 1), with heterogeneity $\left[\chi^{2}=80.17\right.$, degrees of free$\operatorname{dom}(d f)=47, p=0.002]$. Subgroup analysis for the three detection techniques revealed a homogeneous distribution if Tc99m only was used ( $\left.\chi^{2}=16.10, d f=9, p=0.065\right)$. Studies including Tc $99 \mathrm{~m}$ colloid combined with blue dye were heterogeneous $\left(\chi^{2}=45.55, d f=28, p=0.02\right)$. Also, studies in which blue dye was used were heterogeneous $\left(\chi^{2}=18.37, d f=7, p=0.01\right)$. Tc99m used in a combination with blue dye yielded a pooled sensitivity of 0.88 , but Tc99m use alone had the same pooled sensitivity of 0.87 blue dye used alone.

The pooled detection rate was $0.93 \quad(95 \%$ CI 0.92-0.94). No significant differences between tracers used were identified (detection rate: Tc99m 0.90 [95\% CI 0.87-0.93], blue dye 0.87 [95\% CI 0.84-0.90], combined Tc99m and blue dye 0.97 [95 \% CI 0. 87-0.93]). The pooled detection rate of laparotomy versus laparoscopy versus robot-assisted surgery was $0.87 \quad(95 \%$ CI 0.83-0.91), 0.93 (95\% CI 0.90-0.96), and 0.92 (95\% CI $0.88-0.95)$, not significantly different $(p>0.05)$. Also, sensitivity did not significantly differ among laparotomy, 0.86 (95\% CI 0.80-0.90); laparoscopy, 0.90 (95\% CI 0.86-0.94); and robot-assisted surgery, 0.84 (95\% CI $0.72-0.92)$.

\section{Discussion}

Detection of lymph node metastasis in early cervical cancer is crucial for guiding subsequent treatment. In this metaanalysis, we included 49 studies (2,476 various SLN procedures) and quantified pooled sensitivities and detection rates. Each procedure had high sensitivity for SLN detection (rate: 0.93 [95 \% CI 0.92-0.94], sensitivity: 0.88 [95\% CI 0.84-0.91]), which was similar to those achieved in patients with breast cancer (sensitivity 0.91) [9]. Our work documents that SLN procedures are appropriately diagnostic for assessment of nodal metastases in patients with early stage cervical cancer.

FIGO clinical stages correlate with prognosis and anatomical extent of the disease but underestimates pathological extents of disease. Also, nodal involvement, an important independent prognostic factor, is often not incorporated into current FIGO classifications. SLN surgical procedures and detailed assessment should be standard care for early cervical cancer patients. We suggest that for every patient diagnosed with early cervical cancer without clinical evidence of lymph node involvement or 


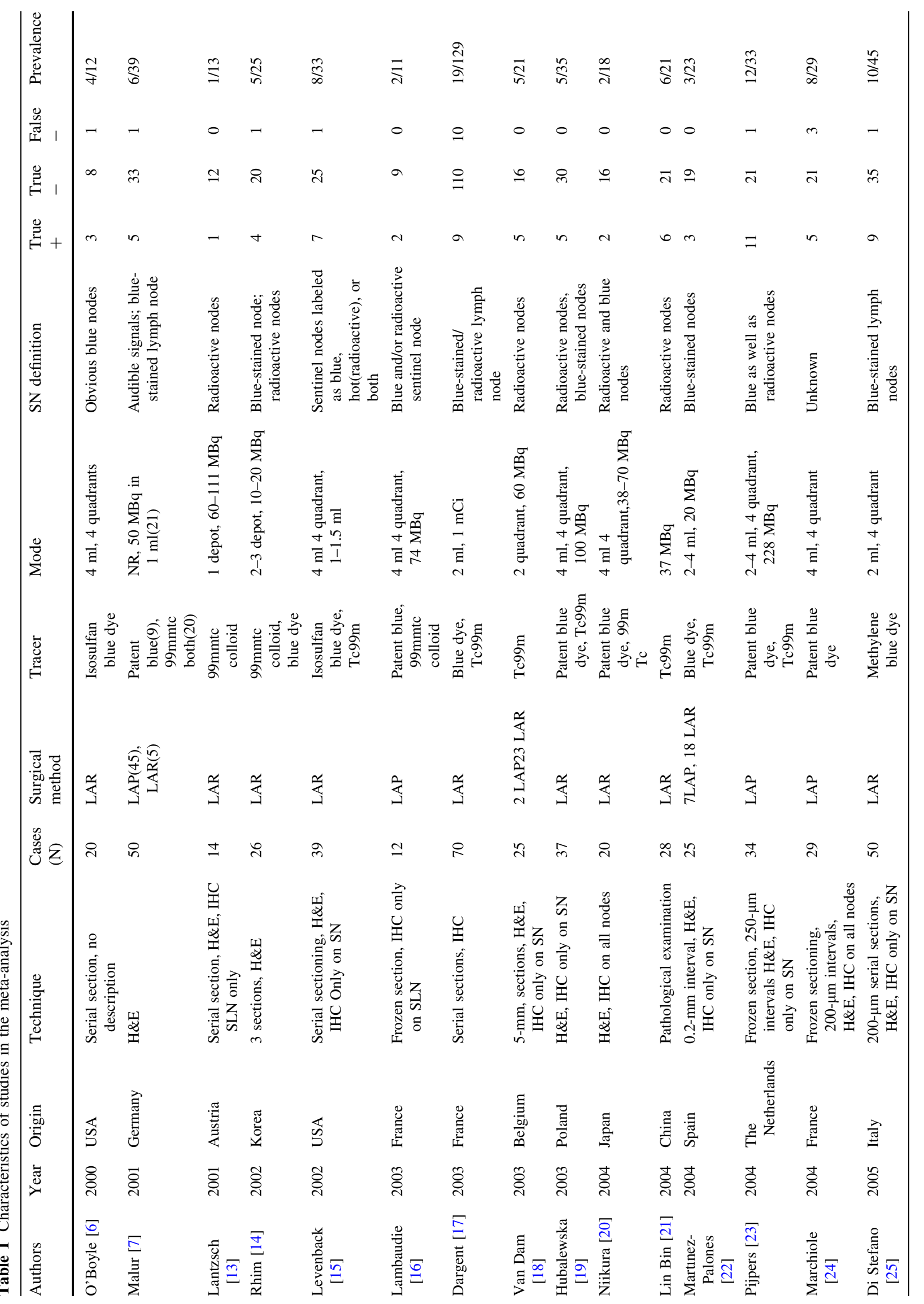




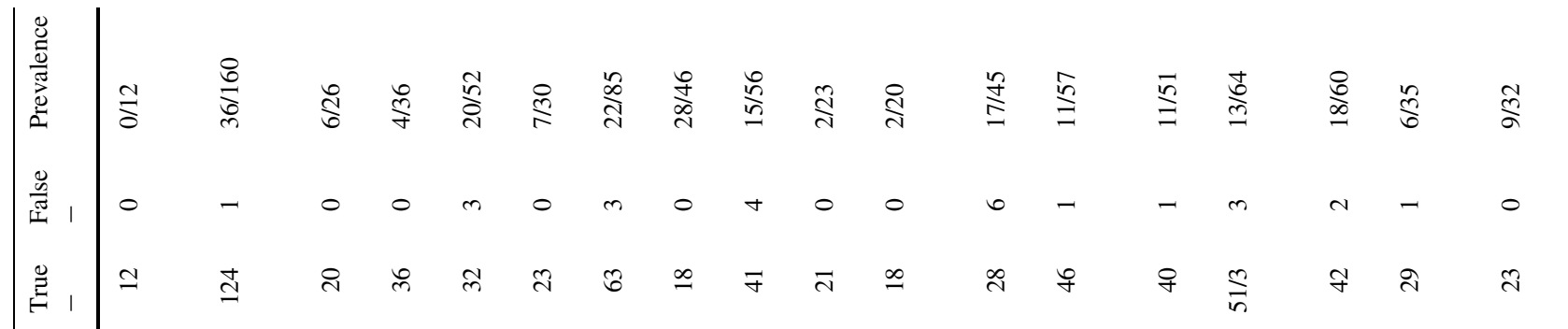

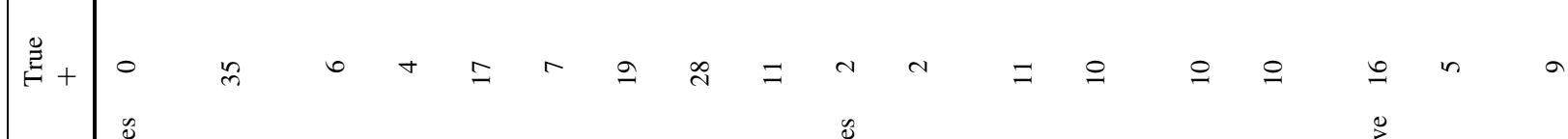

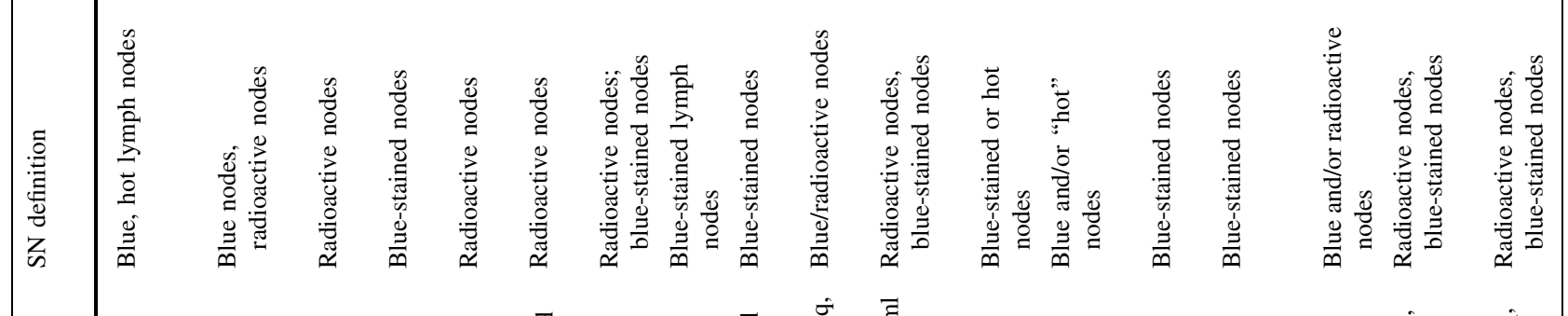

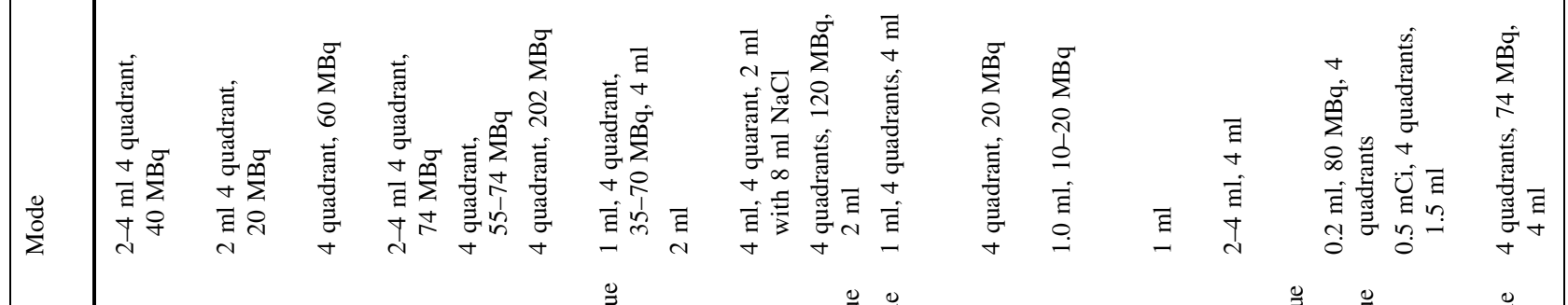

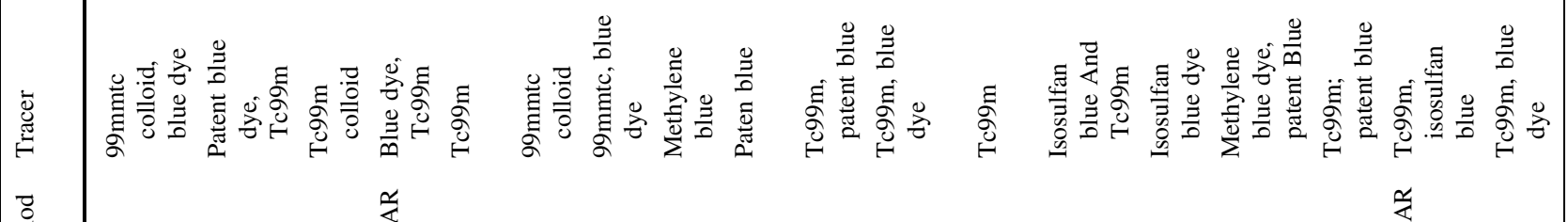

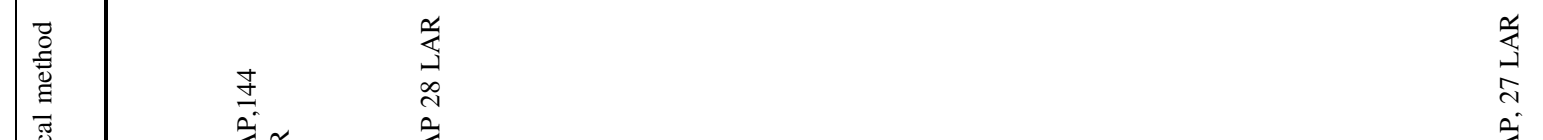

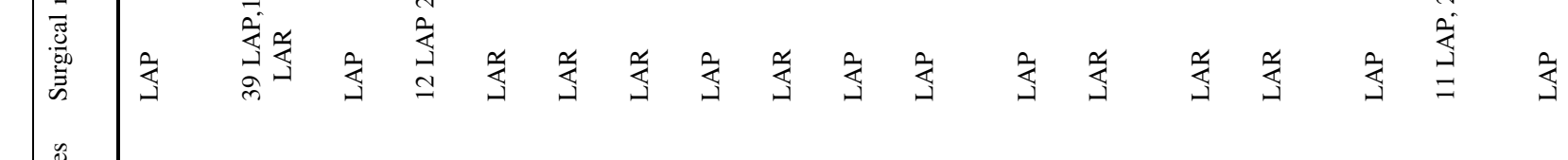

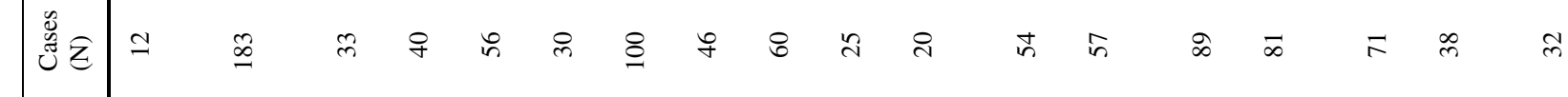

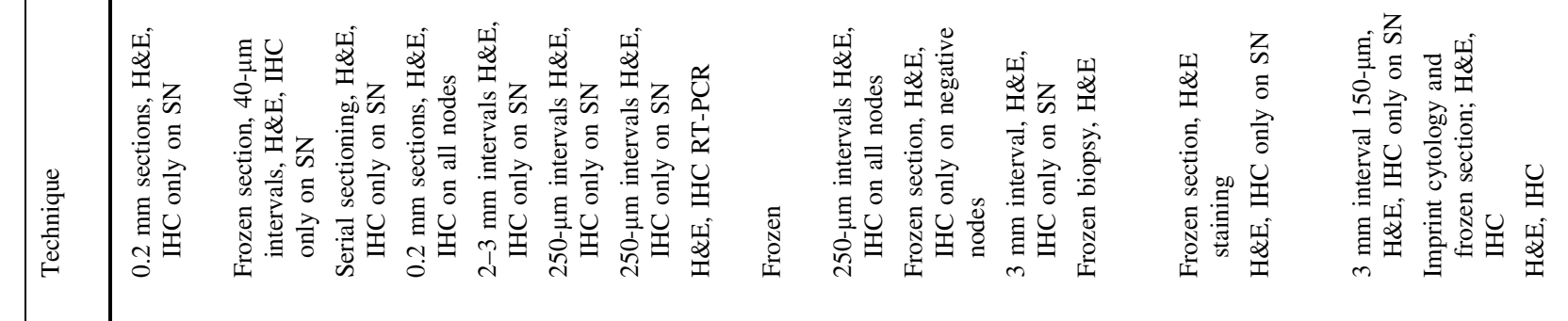

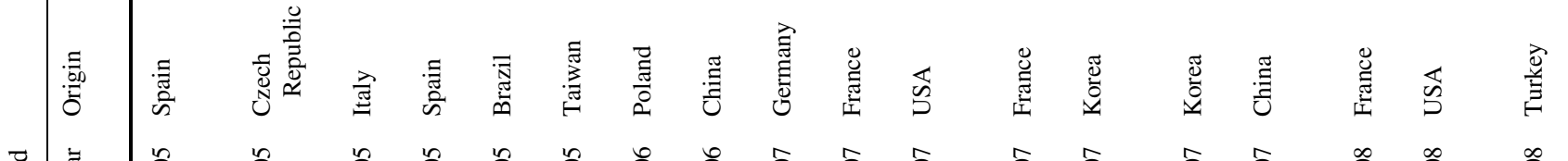 营

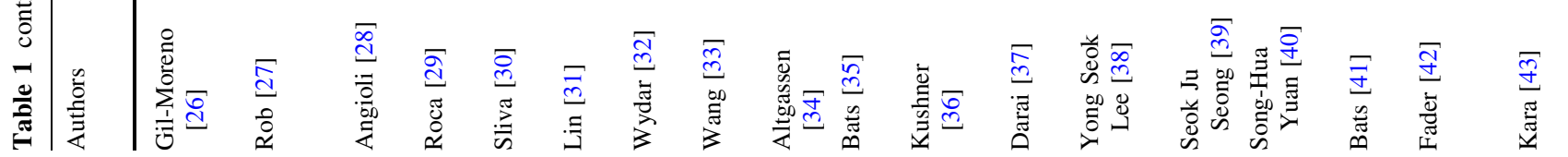




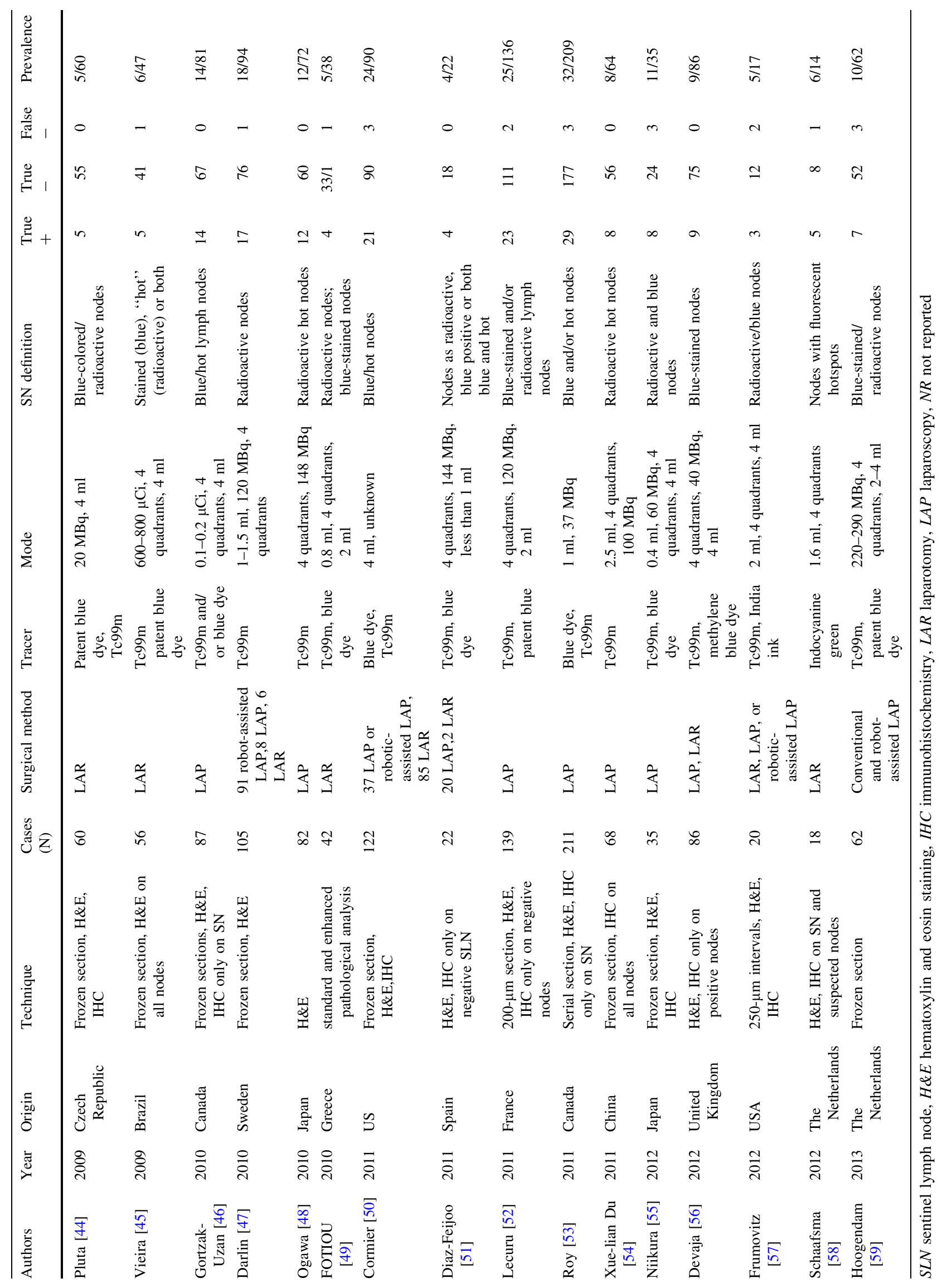




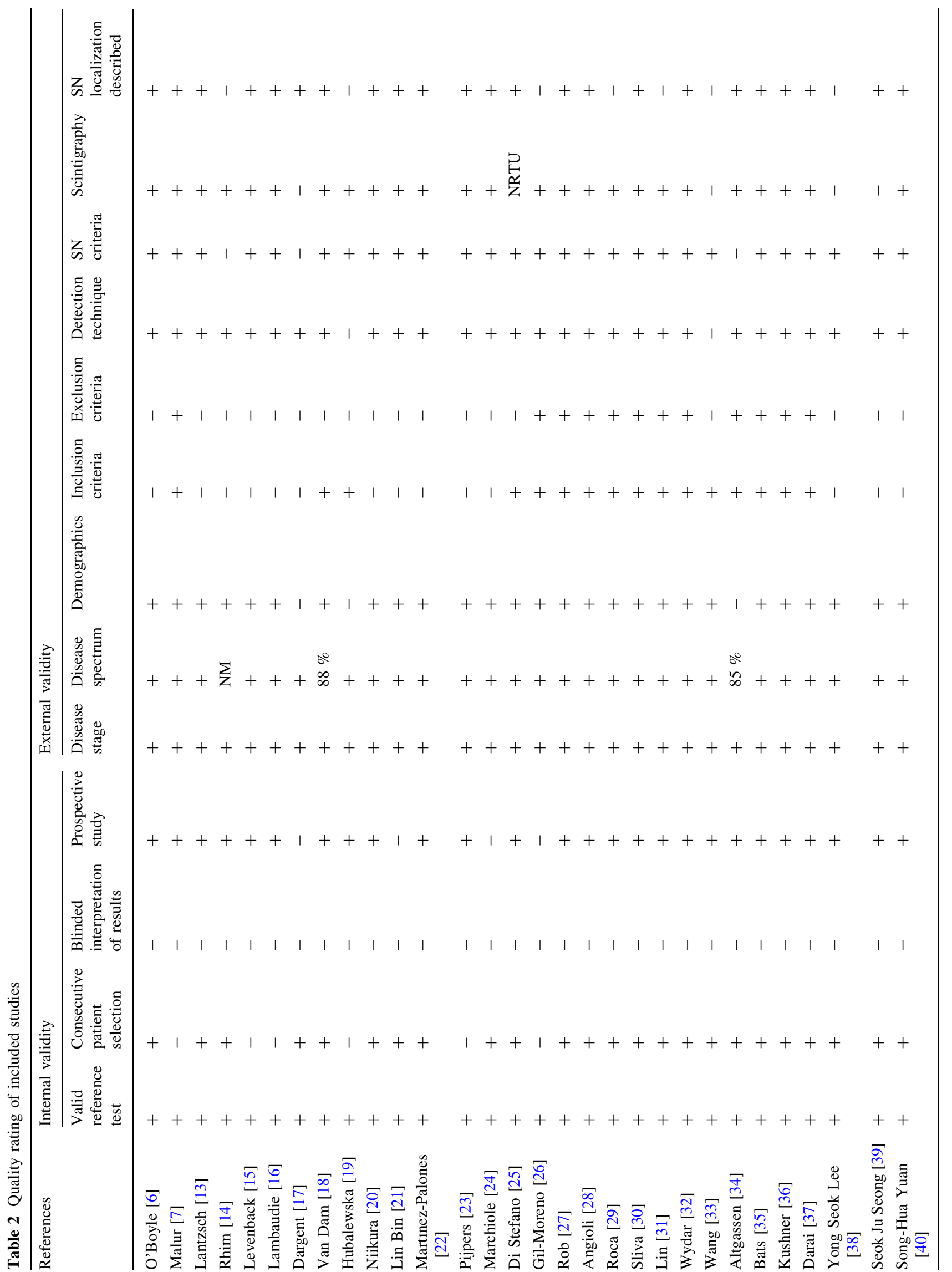




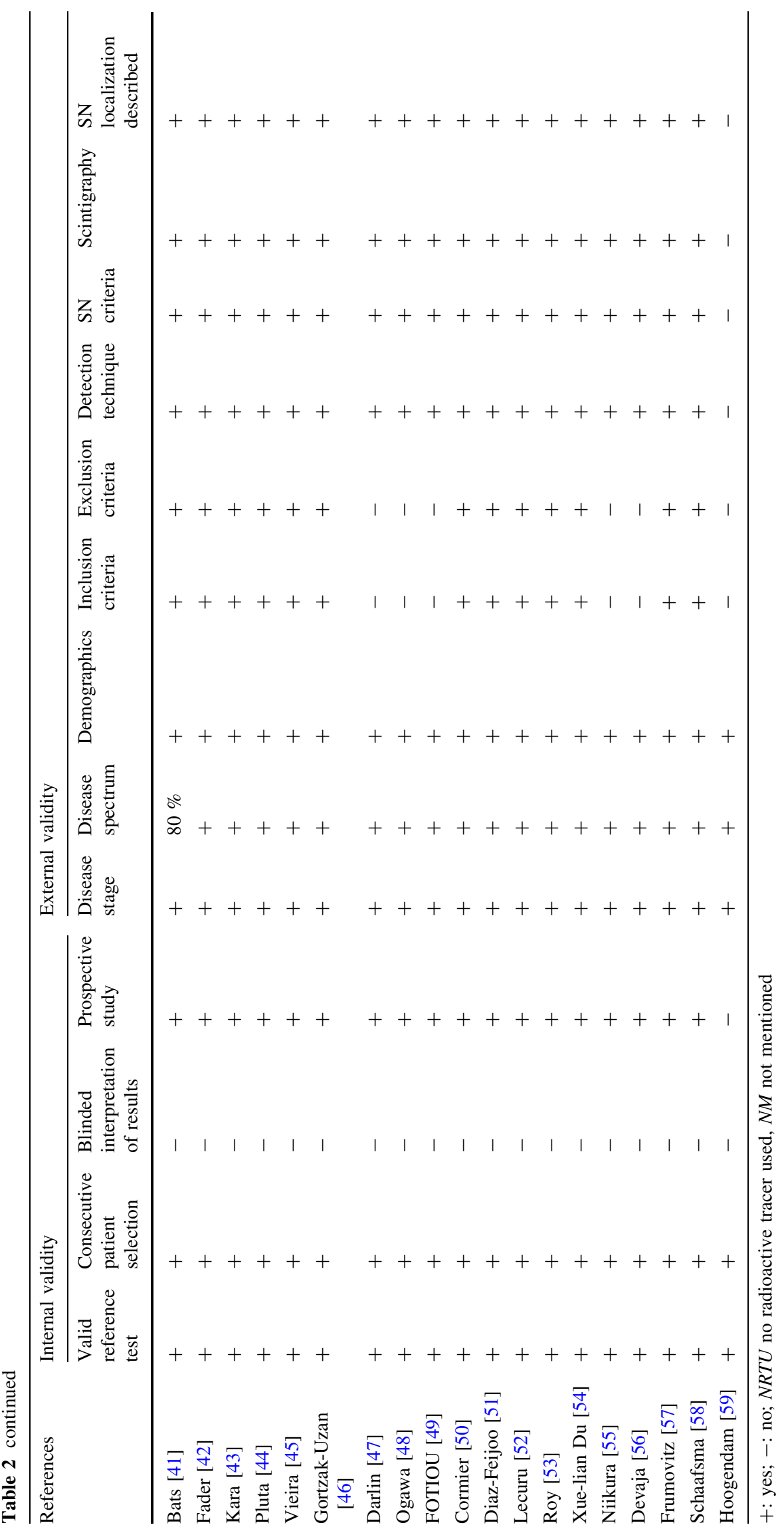


Fig. 1 Weighted sensitivity for each individual study

\section{Weighted sensitivity for each individual study}

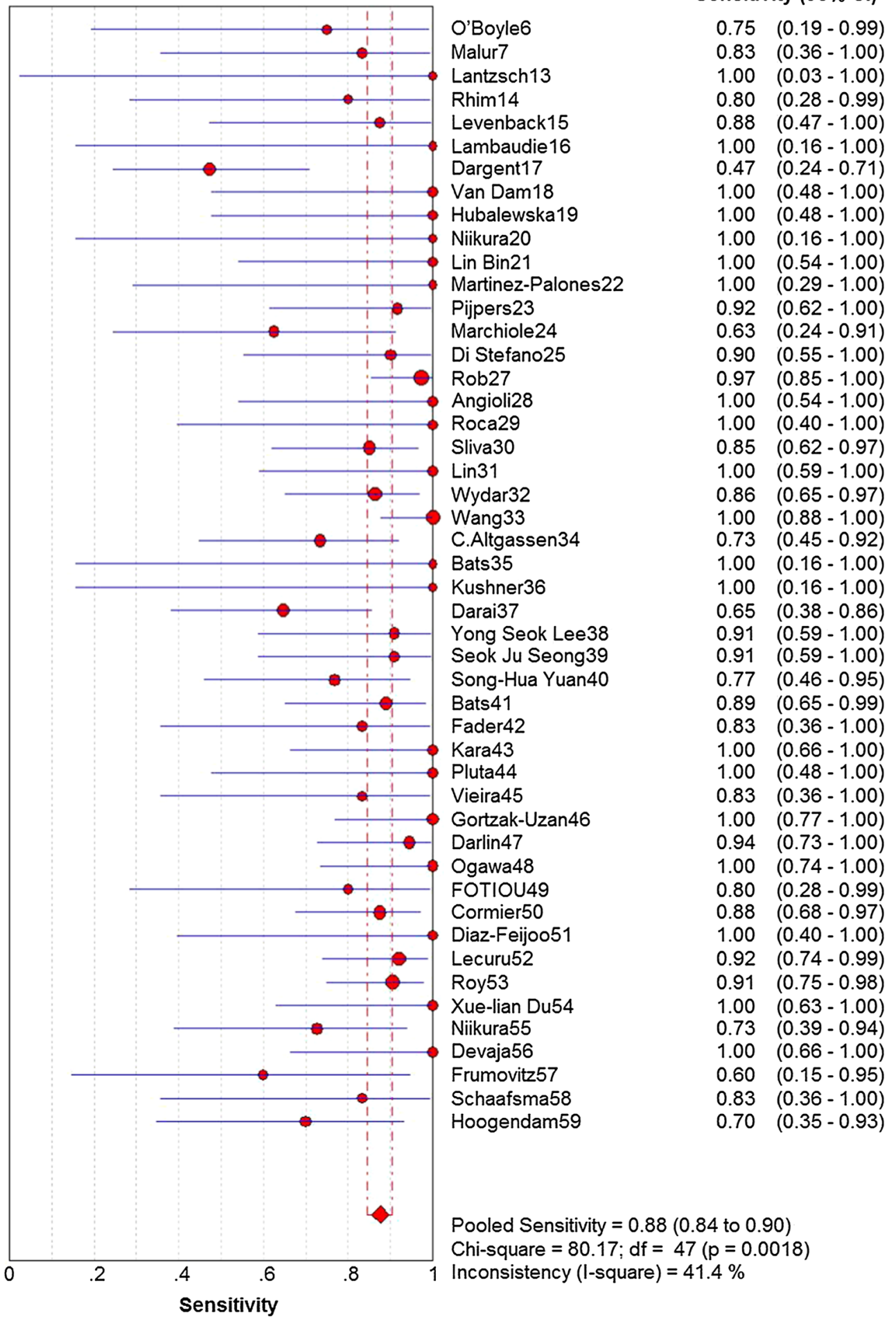

Sensitivity $(95 \% \mathrm{Cl})$

$0.80 \quad(0.28-0.99)$

. $88 \quad(0.47-1.00)$

$(0.16-1.00)$

$.00(0.48-1.00)$

(0.16-1.00)

$00 \quad(0.54-1.00)$

$.00 \quad(0.29-1.00)$

$92(0.62-1.00)$

(0.24-0.91)

$0.90 \quad(0.55-1.00)$

(0.85-1.00)

$(0.54-1.00)$

$100 \quad(0.59-1.00)$

$.86 \quad(0.65-0.97)$

$100 \quad(0.88-1.00)$

. $73 \quad(0.45-0.92)$

$100 \quad(0.16-1.00)$

$1.00 \quad(0.16-1.00)$

$0.65 \quad(0.38-0.86)$

$91 \quad(0.59-1.00)$

(0.59-1.00)

$.77 \quad(0.46-0.95)$

$0.89 \quad(0.65-0.99)$

$03(0.36-1.00)$

$(0.66-1.00)$

$1.00 \quad(0.48-1.00)$

$(0.36-1.00)$

(0.77-1.00)

$.94 \quad(0.73-1.00)$

$1.00 \quad(0.74-1.00)$

(0.80 $(0.28-0.99)$

$(0.68-0.97)$

$1.00(0.66-1.00)$

$0.60 \quad(0.15-0.95)$

(0.36-1.00)

$0.70(0.35-0.93)$ metastatic disease, especially for those women desiring to retain fertility SLN procedures should be considered.

Better diagnostic technology and screening allows earlier detection of cervical cancer and ideally less metastases to lymph nodes. Currently, cervical cancer is diagnosed by endoscopic biopsy, followed by HPV testing and cervical cytology. Also, ultrasonography (US), computed tomography $(\mathrm{CT})$, and magnetic resonance imaging (MRI) are routinely used for treatment planning, but their results do not alter the FIGO disease stages. Thus, morbidity and 
mortality due to unnecessary extensive resection, including para-aortic lymph node resection, will increase [8]. SLN offers prognosis and decreased need for extensive surgery.

Van de Lande and colleagues [70] published a systematic review using selected studies of the SLN procedure in patients with early cervical cancer. They compared techniques (blue dye, Tc99m, or the combined method) and report the highest success rate in terms of detection rate and sensitivity. A total of 23 studies (including 842 patients) were investigated, indicating the greatest $\mathrm{SN}$ detection rate (0.97) with the combined method which had a sensitivity of 0.92. These data are similar to our findings. Also, we compared studies using different surgery methods (laparotomy, laparoscopy, and robot-assisted surgery). SN detection rates and sensitivity of robot-assisted surgery were homogeneous, perhaps because they were so few (only four studies and these included laparotomy and laparoscopy).

Overall treatment decisions based on SLN assessment alone is still not optimal, because of wide variations in reported results due to patient population differences and unique methods used for SLN identification and definition. Our pooled estimates represent average overall effects, and improved methods of SLN assessment in early cervical cancer are needed, including tracer identification, prognostic value of micrometases and isolated tumor cells, patient selection, and surgical expertise.

Techniques used for lymph node assessment most probably influence SNL procedure sensitivity. Detailed assessment of SNLs should increase sensitivity more than single-section H\&E assessment. Therefore, the most accurate study protocol should include the same pathological assessment for SLN and non-sentinel nodes. Variation in pathological techniques used across reports prevented a full analysis.

However, our review is limited. First, selective reporting bias occurs in many clinical fields, including diagnostic testing. The exclusion of conference abstracts, letters to the editor, and non-English-language studies may have led to publication bias. Second, a wide variation in patient selection, SLN procedures, surgeons, pathological techniques, and heterogeneity across institutions may have affected estimates of diagnostic accuracy. Also, due to the combination of heterogeneous results used for our analysis, our findings should be applied in an epidemiological sense and not to establish criteria for patient selection.

\section{Conclusions}

Sentinel-lymph-node performs well diagnostically for assessing nodal metastases in patients with early stage cervical cancer. Large, multicenter studies with strict and homogenous patient selection and standardized SLN procedures and pathological techniques are required to investigate any added value of SLN in the future.

Conflict of interest The authors declare that there are no conflicts of interests.

Open Access This article is distributed under the terms of the Creative Commons Attribution License which permits any use, distribution, and reproduction in any medium, provided the original author(s) and the source are credited.

\section{References}

1. Jemal A, Bray F, Center MM, Ferlay J, Ward E, Forman D. Global cancer statistics. CA Cancer J Clin. 2011;61(2):69-90.

2. Siegel R, Naishadham D, Jemal A. Cancer statistics, 2013. CA Cancer J Clin. 2013;63(1):11-30.

3. Jemal A, Siegel R, Ward E, Murray T, Xu J, Thun MJ. Cancer statistics, 2007. CA Cancer J Clin. 2007;57(1):43-66.

4. Sakuragi N. Up-to-date management of lymph node metastasis and the role of tailored lymphadenectomy in cervical cancer. Int J Clin Oncol. 2007;12(3):165-75.

5. Darai E, Rouzier R, Ballester M, Barranger E, Coutant C. Sentinel lymph node biopsy in gynaecological cancers: the importance of micrometastases in cervical cancer. Surg Oncol. 2008;17(3):227-35. doi:10.1016/j.suronc.2008.04.002.

6. Wang HY, Sun JM, Lu HF, Shi DR, Ou ZL, Ren YL, et al. Micrometastases detected by cytokeratin 19 expression in sentinel lymph nodes of patients with early-stage cervical cancer. Int J Gynecol Cancer. 2006;16(2):643-8. doi:10.1111/j.1525-1438. 2006.00381.x.

7. Martinez-Palones JM, Gil-Moreno A, Perez-Benavente MA, Roca I, Xercavins J. Intraoperative sentinel node identification in early stage cervical cancer using a combination of radiolabeled albumin injection and isosulfan blue dye injection. Gynecol Oncol. 2004;92(3):845-50. doi:10.1016/j.ygyno.2003.11.028.

8. Beesley V, Janda M, Eakin E, Obermair A, Battistutta D. Lymphedema after gynecological cancer treatment. Cancer. 2007;109(12):2607-14.

9. Veronesi U, Paganelli G, Viale G, Luini A, Zurrida S, Galimberti $\mathrm{V}$, et al. A randomized comparison of sentinel-node biopsy with routine axillary dissection in breast cancer. $\mathrm{N}$ Engl J Med. 2003;349(6):546-53.

10. Morton DL, Thompson JF, Cochran AJ, Mozzillo N, Elashoff R, Essner R, et al. Sentinel-node biopsy or nodal observation in melanoma. N Engl J Med. 2006;355(13):1307-17.

11. Whiting P, Rutjes AWS, Reitsma JB, Bossuyt PMM, Kleijnen J. The development of QUADAS: a tool for the quality assessment of studies of diagnostic accuracy included in systematic reviews. BMC Med Res Methodol. 2003;3(1):1-13.

12. O'Boyle JD, Coleman RL, Bernstein SG, Lifshitz S, Muller CY, Miller DS. Intraoperative lymphatic mapping in cervix cancer patients undergoing radical hysterectomy: a pilot study. Gynecol Oncol. 2000;79(2):238-43. doi:10.1006/gyno.2000.5930.

13. Lantzsch T, Wolters M, Grimm J, Mende T, Buchmann J, Sliutz $\mathrm{G}$, et al. Sentinel node procedure in Ib cervical cancer: a preliminary series. Br J Cancer. 2001;85(6):791-4. doi:10.1054/bjoc. 2001.2005.

14. Malur S, Krause N, Kohler C, Schneider A. Sentinel lymph node detection in patients with cervical cancer. Gynecol Oncol. 2001;80(2):254-7. doi:10.1006/gyno.2000.6041. 
15. Rhim CC, Park JS, Bae SN, Namkoong SE. Sentinel node biopsy as an indicator for pelvic nodes dissection in early stage cervical cancer. J Korean Med Sci. 2002;17(4):507-11.

16. Levenback C, Coleman RL, Burke TW, Lin WM, Erdman W, Deavers $\mathrm{M}$, et al. Lymphatic mapping and sentinel node identification in patients with cervix cancer undergoing radical hysterectomy and pelvic lymphadenectomy. J Clin Oncol. 2002;20(3):688-93.

17. Lambaudie E, Collinet $P$, Narducci F, Sonoda Y, Papageorgiou T, Carpentier P, et al. Laparoscopic identification of sentinel lymph nodes in early stage cervical cancer: prospective study using a combination of patent blue dye injection and technetium radiocolloid injection. Gynecol Oncol. 2003;89(1):84-7.

18. Dargent D, Enria R. Laparoscopic assessment of the sentinel lymph nodes in early cervical cancer. Technique-preliminary results and future developments. Crit Rev Oncol Hematol. 2003;48(3):305-10.

19. van Dam PA, Hauspy J, Vanderheyden T, Sonnemans H, Spaepen A, Eggenstein G, et al. Intraoperative sentinel node identification with Technetium-99m-labeled nanocolloid in patients with cancer of the uterine cervix: a feasibility study. Int J Gynecol Cancer. 2003;13(2):182-6.

20. Hubalewska A, Sowa-Staszczak A, Huszno B, Markocka A, Pitynski K, Basta A, et al. Use of Tc99m-nanocolloid for sentinel nodes identification in cervical cancer. Nucl Med Rev Cent East Eur. 2003;6(2):127-30.

21. Niikura H, Okamura C, Akahira J, Takano T, Ito K, Okamura K, et al. Sentinel lymph node detection in early cervical cancer with combination $99 \mathrm{mTc}$ phytate and patent blue. Gynecol Oncol. 2004;94(2):528-32. doi:10.1016/j.ygyno.2004.05.016.

22. Li B, Zhang WH, Liu L, Wu LY, Zhang R, Li N. Sentinel lymph node identification in patients with early stage cervical cancer undergoing radical hysterectomy and pelvic lymphadenectomy. Chin Med J (Engl). 2004;117(6):867-70.

23. Pijpers R, Buist MR, van Lingen A, Dijkstra J, van Diest PJ, Teule GJ, et al. The sentinel node in cervical cancer: scintigraphy and laparoscopic gamma probe-guided biopsy. Eur J Nucl Med Mol Imaging. 2004;31(11):1479-86. doi:10.1007/s00259-004-1563-4.

24. Marchiolè P, Buénerd A, Scoazec J-Y, Dargent D, Mathevet P. Sentinel lymph node biopsy is not accurate in predicting lymph node status for patients with cervical carcinoma. Cancer. 2004;100(10):2154-9. doi:10.1002/cncr.20212.

25. Di Stefano AB, Acquaviva G, Garozzo G, Barbic M, Cvjeticanin B, Meglic L, et al. Lymph node mapping and sentinel node detection in patients with cervical carcinoma: a 2-year experience. Gynecol Oncol. 2005;99(3):671-9. doi:10.1016/j.ygyno. 2005.07.115.

26. Gil-Moreno A, Diaz-Feijoo B, Roca I, Puig O, Perez-Benavente MA, Aguilar I, et al. Total laparoscopic radical hysterectomy with intraoperative sentinel node identification in patients with early invasive cervical cancer. Gynecol Oncol. 2005;96(1):187-93. doi:10.1016/j.ygyno.2004.09.055.

27. Rob L, Strnad P, Robova H, Charvat M, Pluta M, Schlegerova D, et al. Study of lymphatic mapping and sentinel node identification in early stage cervical cancer. Gynecol Oncol. 2005;98(2):281-8. doi:10.1016/j.ygyno.2005.04.016.

28. Angioli R, Palaia I, Cipriani C, Muzii L, Calcagno M, Gullotta G, et al. Role of sentinel lymph node biopsy procedure in cervical cancer: a critical point of view. Gynecol Oncol. 2005;96(2):504-9. doi:10.1016/j.ygyno.2004.10.034.

29. Roca I, Caresia AP, Gil-Moreno A, Pifarre P, Aguade-Bruix S, Castell-Conesa $\mathbf{J}$, et al. Usefulness of sentinel lymph node detection in early stages of cervical cancer. Eur J Nucl Med Mol Imaging. 2005;32(10):1210-6. doi:10.1007/s00259-005-1834-8.

30. Silva LB, Silva-Filho AL, Traiman P, Triginelli SA, de Lima CF, Siqueira CF, et al. Sentinel node detection in cervical cancer with
(99m)Tc-phytate. Gynecol Oncol. 2005;97(2):588-95. doi:10. 1016/j.ygyno.2005.02.014.

31. Lin YS, Tzeng CC, Huang KF, Kang CY, Chia CC, Hsieh JF. Sentinel node detection with radiocolloid lymphatic mapping in early invasive cervical cancer. Int $\mathrm{J}$ Gynecol Cancer. 2005;15(2):273-7. doi:10.1111/j.1525-1438.2005.15215.x.

32. Wydra D, Sawicki S, Wojtylak S, Bandurski T, Emerich J. Sentinel node identification in cervical cancer patients undergoing transperitoneal radical hysterectomy: a study of 100 cases. Int J Gynecol Cancer. 2006;16(2):649-54. doi:10.1111/j.1525-1438. 2006.00402.x.

33. Altgassen C, Paseka A, Urbanczyk H, Dimpfl T, Diedrich K, Dahmen $\mathrm{G}$, et al. Dilution of dye improves parametrial SLN detection in patients with cervical cancer. Gynecol Oncol. 2007;105(2):329-34. doi:10.1016/j.ygyno.2006.12.009.

34. Bats AS, Clement D, Larousserie F, Lefrere-Belda MA, Faraggi M, Froissart M, et al. Sentinel lymph node biopsy improves staging in early cervical cancer. Gynecol Oncol. 2007;105(1):189-93. doi:10.1016/j.ygyno.2006.11.021.

35. Kushner DM, Connor JP, Wilson MA, Hafez GR, Chappell RJ, Stewart SL, et al. Laparoscopic sentinel lymph node mapping for cervix cancer-a detailed evaluation and time analysis. Gynecol Oncol. 2007;106(3):507-12. doi:10.1016/j.ygyno.2007.04.031.

36. Darai E, Lavoue V, Rouzier R, Coutant C, Barranger E, Bats AS. Contribution of the sentinel node procedure to tailoring the radicality of hysterectomy for cervical cancer. Gynecol Oncol. 2007;106(1):251-6. doi:10.1016/j.ygyno.2007.03.034.

37. Lee YS, Rhim CC, Lee HN, Lee KH, Park JS, Namkoong SE. HPV status in sentinel nodes might be a prognostic factor in cervical cancer. Gynecol Oncol. 2007;105(2):351-7. doi:10. 1016/j.ygyno.2006.12.016.

38. Seong SJ, Park H, Yang KM, Kim TJ, Lim KT, Shim JU, et al. Detection of sentinel lymph nodes in patients with early stage cervical cancer. J Korean Med Sci. 2007;22(1):105-9.

39. Yuan SH, Xiong Y, Wei M, Yan XJ, Zhang HZ, Zeng YX, et al. Sentinel lymph node detection using methylene blue in patients with early stage cervical cancer. Gynecol Oncol. 2007;106(1):147-52. doi:10.1016/j.ygyno.2007.03.037.

40. Bats AS, Lavoue V, Rouzier R, Coutant C, Kerrou K, Darai E. Limits of day-before lymphoscintigraphy to localize sentinel nodes in women with cervical cancer. Ann Surg Oncol. 2008;15(8):2173-9. doi:10.1245/s10434-008-9897-y.

41. Fader AN, Edwards RP, Cost M, Kanbour-Shakir A, Kelley JL, Schwartz B, et al. Sentinel lymph node biopsy in early-stage cervical cancer: utility of intraoperative versus postoperative assessment. Gynecol Oncol. 2008;111(1):13-7. doi:10.1016/j. ygyno.2008.06.009.

42. Kara PP, Ayhan A, Caner B, Gultekin M, Ugur O, Bozkurt MF, et al. Sentinel lymph node detection in early stage cervical cancer: a prospective study comparing preoperative lymphoscintigraphy, intraoperative gamma probe, and blue dye. Ann Nucl Med. 2008;22(6):487-94. doi:10.1007/s12149-008-0144-1.

43. Vieira SC, Sousa RB, Tavares MB, Silva JB, Abreu BA, Santos LG, et al. Preoperative pelvic lymphoscintigraphy is of limited usefulness for sentinel lymph node detection in cervical cancer. Eur J Obstet Gynecol Reprod Biol. 2009;145(1):96-9. doi:10. 1016/j.ejogrb.2009.03.025.

44. Pluta M, Rob L, Charvat M, Chmel R, Halaska M Jr, Skapa P, et al. Less radical surgery than radical hysterectomy in early stage cervical cancer: a pilot study. Gynecol Oncol. 2009;113(2):181-4. doi:10.1016/j.ygyno.2009.02.005.

45. Gortzak-Uzan L, Jimenez W, Nofech-Mozes S, Ismiil N, Khalifa MA, Dube V, et al. Sentinel lymph node biopsy vs. pelvic lymphadenectomy in early stage cervical cancer: is it time to change the gold standard? Gynecol Oncol. 2010;116(1):28-32. doi:10. 1016/j.ygyno.2009.10.049. 
46. Darlin L, Persson J, Bossmar T, Lindahl B, Kannisto P, Masback A, et al. The sentinel node concept in early cervical cancer performs well in tumors smaller than $2 \mathrm{~cm}$. Gynecol Oncol. 2010;117(2):266-9. doi:10.1016/j.ygyno.2010.01.035.

47. Ogawa S, Kobayashi H, Amada S, Yahata H, Sonoda K, Abe K, et al. Sentinel node detection with $(99 \mathrm{~m}) \mathrm{Tc}$ phytate alone is satisfactory for cervical cancer patients undergoing radical hysterectomy and pelvic lymphadenectomy. Int $\mathrm{J}$ Clin Oncol. 2010;15(1):52-8. doi:10.1007/s10147-009-0010-8.

48. Cormier B, Diaz JP, Shih K, Sampson RM, Sonoda Y, Park KJ, et al. Establishing a sentinel lymph node mapping algorithm for the treatment of early cervical cancer. Gynecol Oncol. 2011;122(2):275-80. doi:10.1016/j.ygyno.2011.04.023.

49. Fotiou S, Zarganis P, Vorgias G, Trivizaki E, Velentzas K, Akrivos $\mathrm{T}$, et al. Clinical value of preoperative lymphoscintigraphy in patients with early cervical cancer considered for intraoperative lymphatic mapping. Anticancer Res. 2010;30(1):183-8.

50. Diaz-Feijoo B, Perez-Benavente MA, Cabrera-Diaz S, Gil-Moreno A, Roca I, Franco-Camps S, et al. Change in clinical management of sentinel lymph node location in early stage cervical cancer: the role of SPECT/CT. Gynecol Oncol. 2011;120(3):353-7. doi:10.1016/j.ygyno.2010.12.336.

51. Lecuru F, Mathevet P, Querleu D, Leblanc E, Morice P, Darai E, et al. Bilateral negative sentinel nodes accurately predict absence of lymph node metastasis in early cervical cancer: results of the SENTICOL study. J Clin Oncol. 2011;29(13):1686-91. doi:10. 1200/JCO.2010.32.0432.

52. Roy M, Bouchard-Fortier G, Popa I, Gregoire J, Renaud MC, Tetu B, et al. Value of sentinel node mapping in cancer of the cervix. Gynecol Oncol. 2011;122(2):269-74. doi:10.1016/j. ygyno.2011.04.002.

53. Du XL, Sheng XG, Jiang T, Li QS, Yu H, Pan CX, et al. Sentinel lymph node biopsy as guidance for radical trachelectomy in young patients with early stage cervical cancer. BMC Cancer. 2011;11:157. doi:10.1186/1471-2407-11-157.

54. Niikura H, Okamoto S, Otsuki T, Yoshinaga K, Utsunomiya H, Nagase $S$, et al. Prospective study of sentinel lymph node biopsy without further pelvic lymphadenectomy in patients with sentinel lymph node-negative cervical cancer. Int J Gynecol Cancer. 2012;22(7):1244-50. doi:10.1097/IGC.0b013e318263f06a.

55. Frumovitz M, Euscher ED, Deavers MT, Soliman PT, Schmeler KM, Ramirez PT, et al. "Triple injection" lymphatic mapping technique to determine if parametrial nodes are the true sentinel lymph nodes in women with cervical cancer. Gynecol Oncol. 2012;127(3):467-71. doi:10.1016/j.ygyno.2012.08.015.

56. Schaafsma BE, van der Vorst JR, Gaarenstroom KN, Peters AA, Verbeek FP, de Kroon CD, et al. Randomized comparison of near-infrared fluorescence lymphatic tracers for sentinel lymph node mapping of cervical cancer. Gynecol Oncol. 2012;127(1):126-30. doi:10.1016/j.ygyno.2012.07.002.

57. Devaja O, Mehra G, Coutts M, Montalto SA, Donaldson J, Kodampur $\mathrm{M}$, et al. A prospective single-center study of sentinel lymph node detection in cervical carcinoma: is there a place in clinical practice? Int J Gynecol Cancer. 2012;22(6):1044-9. doi:10.1097/IGC.0b013e318253a9c9.

58. Hoogendam JP, Hobbelink MG, Veldhuis WB, Verheijen RH, van Diest PJ, Zweemer RP. Preoperative sentinel node mapping with (99m)Tc-nanocolloid SPECT-CT significantly reduces the intraoperative sentinel node retrieval time in robot assisted laparoscopic cervical cancer surgery. Gynecol Oncol. 2013;129(2):389-94. doi:10.1016/j.ygyno.2013.02.020.

59. Verheijen RH, Pijpers R, van Diest PJ, Burger CW, Buist MR, Kenemans P. Sentinel node detection in cervical cancer. Obstet Gynecol. 2000;96(1):135-8.

60. Crane LM, Themelis G, Pleijhuis RG, Harlaar NJ, Sarantopoulos $\mathrm{A}$, Arts $\mathrm{HJ}$, et al. Intraoperative multispectral fluorescence imaging for the detection of the sentinel lymph node in cervical cancer: a novel concept. Mol Imaging Biol. 2011;13(5):1043-9. doi:10.1007/s11307-010-0425-7.

61. Buist MR, Pijpers RJ, van Lingen A, van Diest PJ, Dijkstra J, Kenemans P, et al. Laparoscopic detection of sentinel lymph nodes followed by lymph node dissection in patients with early stage cervical cancer. Gynecol Oncol. 2003;90(2):290-6.

62. Chung YA, Kim SH, Sohn HS, Chung SK, Rhim CC, Namkoong SE. Usefulness of lymphoscintigraphy and intraoperative gamma probe detection in the identification of sentinel nodes in cervical cancer. Eur J Nucl Med Mol Imaging. 2003;30(7):1014-7. doi:10.1007/s00259-003-1195-0.

63. Hauspy J, Beiner M, Harley I, Ehrlich L, Rasty G, Covens A. Sentinel lymph nodes in early stage cervical cancer. Gynecol Oncol. 2007;105(2):285-90. doi:10.1016/j.ygyno.2007.02.008.

64. Coutant C, Morel O, Delpech Y, Uzan S, Darai E, Barranger E. Laparoscopic sentinel node biopsy in cervical cancer using a combined detection: 5-years experience. Ann Surg Oncol. 2007;14(8):2392-9. doi:10.1245/s10434-007-9424-6.

65. Abu-Rustum NR, Neubauer N, Sonoda Y, Park KJ, Gemignani M, Alektiar KM, et al. Surgical and pathologic outcomes of fertility-sparing radical abdominal trachelectomy for FIGO stage IB1 cervical cancer. Gynecol Oncol. 2008;111(2):261-4. doi:10. 1016/j.ygyno.2008.07.002.

66. Zarganis P, Kondi-Pafiti A, Arapantoni-Dadioti P, Trivizaki E, Velentzas K, Vorgias G, et al. The sentinel node in cervical cancer patients: role of tumor size and invasion of lymphatic vascular space. In Vivo. 2009;23(3):469-73.

67. Martinez A, Zerdoud S, Mery E, Bouissou E, Ferron G, Querleu D. Hybrid imaging by SPECT/CT for sentinel lymph node detection in patients with cancer of the uterine cervix. Gynecol Oncol. 2010;119(3):431-5. doi:10.1016/j.ygyno.2010.08.001.

68. Bats AS, Buenerd A, Querleu D, Leblanc E, Darai E, Morice P, et al. Diagnostic value of intraoperative examination of sentinel lymph node in early cervical cancer: a prospective, multicenter study. Gynecol Oncol. 2011;123(2):230-5. doi:10.1016/j.ygyno. 2011.08.010.

69. Chereau E, Feron JG, Ballester M, Coutant C, Bezu C, Rouzier R, et al. Contribution of pelvic and para-aortic lymphadenectomy with sentinel node biopsy in patients with IB2-IIB cervical cancer. Br J Cancer. 2012;106(1):39-44. doi:10.1038/bjc.2011.541.

70. van de Lande J, Torrenga B, Raijmakers PG, Hoekstra OS, van Baal MW, Brölmann HA, et al. Sentinel lymph node detection in early stage uterine cervix carcinoma: a systematic review. Gynecol Oncol. 2007;106(3):604-13. 